\title{
Changes in plant water status, biochemical attributes and seed quality of black gram and green gram genotypes under drought
}

\author{
B. Baroowa and N. Gogoi
}

Department of Environmental Science, Tezpur University, Tezpur-784028, Assam, India

*e-mail : nirmali@tezu.ernet.in, +91-03712 267007/8 Ext. 5609

\begin{abstract}
Keywords: Drought; leaf area index; leaf water potential; proline; total Flavonoid; anthocyanin; seed protein
\end{abstract}

\begin{abstract}
Drought is one of the major abiotic stresses which adversely affect crop growth and production worldwide as water is vital for every aspect of plant growth and development. The present investigation was carried out during the growing seasons (September - December) of 2012 and 2013 to evaluate the response of black gram (Vigna mungo L.) and green gram (Vigna radiata L.) genotypes in terms of some important growth indices, biochemical traits and seed quality under drought stress. Four commonly grown genotypes- T9, KU 301(black gram) and Pratap, SG 21-5 (green gram) of Assam, India were grown in a randomized block design with three replications under stress and non-stress conditions. Stress was applied by withholding irrigation for fifteen consecutive days at vegetative, flowering and pod filling stages. Leaf area index (LAI), seed protein content and protein yield significantly decreased $(\mathrm{p} \leq 0.01)$ whereas proline, total flavonoids and anthocyanin content increased significantly $(p \leq 0.01)$ in response to water deficiency. Among the studied genotypes, T9 and Pratap showed better tolerance capacity towards the applied drought by presenting higher values of LAI, plant height stress tolerance index (PHSI), dry matter stress tolerance index (DMSI), proline, total flavonoids, anthocyanin, lower percentage of chlorophyll degradation and finally producing high quality seeds.
\end{abstract}

\section{INTRODUCTION}

Water is one of the major components of plant cells, and is the medium in which growth processes occur. Hence shortage of water induces a series of physiological, biochemical and morphological changes in crops leading to drastic loss in yield (Abbasi et al., 2014). However, there are significant differences in the tolerance of plants to drought stress depending upon intensity and duration of stress, plant species and the stage of development (Sing et al., 2012). Drought inhibits linear growth of plants, reduce leaf number per plant and individual leaf size, leaf longevity and dry matter accumulation by decreasing the soil's water potential (Anjum et al., 2011). For many grain legumes, leaf area development (leaf production and expansion) is more sensitive to water stress than leaf abscission (Muchow, 1985).

Deficiency in soil moisture suppresses the rate of photosynthesis by causing changes in chlorophyll content, affecting chlorophyll components and damaging the photosynthetic apparatus (Manivannan et al., 2007). The survival of plants in circumstances of water deficiency is dependent on the osmotic adjustment, which promotes accumulation of a range of osmotically active molecules/ions including soluble sugars, sugar alcohols, proline, organic acids, calcium, potassium, chloride ions, etc. (Farooq et al., 2009). These intracellular osmolytes promote water retention and alleviate negative influence of water deficit in plants. Hence, the accumulation of proline in plant tissues can be considered as a clear marker for environmental stresses, particularly in plants experiencing water deficit stress.

Under drought, increased production of secondary metabolites like flavonoids and phenolics is often observed in plants which is beneficial for resisting the adverse effect of drought (Jaafar et al., 2012). Castaneda-Saucedo et al. (2009) reported a general decreasing trend of total soluble proteins in all plant tissues under water deficit condition. Deficiency of water reduces $\mathrm{N}$ partitioning and fixation (Serraj and Sinclair, 1998), plant and seed uptake and utilization of nutrients (Dos 
Santos et al., 2004). However, in most of the plant species, these biochemical and physiological modifications are not sufficient for survival when severe drought conditions remain constant over time. Thus, the need to develop drought-resistant cultivars is a major challenge for sustainable agriculture (Alcázar et al., 2010).

Black gram (Vigna mungo L.) and Green gram (Vigna radiate L.) are important shortduration grain legumes in developing countries of Asia, Africa and Latin America where they serve as a valuable protein source for human consumption (Karuppanapandian et al., 2006). These two pulses are highly rich in protein $(25-26 \%)$ and amino acids like lysine and tryptophan. They play a major role in enhancing soil fertility through symbiotic nitrogen fixation. In north-eastern part of India, these two crops are subjected to frequent drought due to prevailing erratic and insufficient monsoon rainfall pattern and inadequate irrigation facility. As increased irrigation is not a vital answer to the problem, an economically and environmentally desirable solution is new varieties with decreased sensitivity to water deficits. But, breeding for water stress is also complicated due to lack of fast and reproducible screening techniques (Kelly And Ramirez-Vallejo, 1998). Hence it is important to look for alternative strategies to obtain yield stability and quality in drought prone areas using the presently available varieties. Therefore, the purpose of the present investigation was to test the sensitivity of four commonly grown genotypes (two each of black gram and green gram) to soil water deficit by studying some important growth indices, leaf water status, leaf proline, total flavonoids, anthocyanin, chlorophyll degradation percentage and seed quality in terms of seed protein content and protein yield. Further, we tried to investigate the genotypic variability of the studied genotypes to water deficit at three different growth stages.

\section{MATERIALS AND METHODS}

\subsection{Plant Material and Growth Conditions}

The present investigation was carried out with four popularly grown genotypes- T9, KU 301 (black gram) and Pratap, SG 21-5 (green gram) collected from Regional Agricultural Research Station (RARS), Nagaon (Assam), India during the growing seasons (September - December) of 2012 and 2013. The experimental design was randomized block design with three replications under stress and non-stress conditions. Seeds were sown at the experimental field of Tezpur University campus located at North Bank Plain zone of Assam $\left(26^{\circ} 14^{\prime} \mathrm{N}\right.$ and $\left.92^{\circ} 50^{\prime} \mathrm{E}\right)$ at Tezpur, India maintaining the requisite gap of 10 and $30 \mathrm{~cm}$ between plants and rows respectively. The experimental site was characterized by silt loam textured soil being slightly acidic in nature $(\mathrm{pH}$ 5.85). The maximum and minimum average temperature recorded during the experimental period ranged from 22.74 to $22.96^{\circ} \mathrm{C}$ and the average rainfall recorded was $0.14 \mathrm{~mm}$ with a relative humidity of $82.45 \%$. A temporary rain shed was constructed in the field with PVC (polyvinyl chloride) film (of about $0.15 \mathrm{~mm}$ thickness and $85 \%$ of transmittance) to avoid rainfall. Control plants were grown with proper irrigation throughout the growing period and were denoted as $T_{1}$. Drought treatments for all the genotypes were arranged as $\mathrm{T}_{2}-$ withholding irrigation for 15 days at vegetative stage (25 days after sowing), $\mathrm{T}_{3}$ - withholding irrigation for 15 days at flowering stage (35 days after sowing), $\mathrm{T}_{4}$ - withholding irrigation for 15 days at pod filling stage (45 days after sowing).

In the control plots, soil water potential $\left(\Psi_{\mathrm{S}}\right)$ was maintained at -0.15 to -0.20 bars while in the treatment plots, it ranged from -0.75 to -0.80 bar after withholding of irrigation for 15 days.

\subsection{Growth Indices}

Leaf area was recorded non- destructively by using a laser leaf area meter (model CI-203, USA). Leaf area index was then calculated using the formula given by Moosavi (2012).

$$
\mathrm{LAI}=\frac{\text { Leaf area/ plant }}{\text { Ground surface area/ plant }}
$$


Plant height stress tolerance index (PHSI) and dry matter stress tolerance index (DMSI) was calculated using the formulae given by Nawas et al. (2013).

PHSI $=[$ Plant height of stressed plant $/$ plant height of control plant $] \times 100$

DMSI $=[$ Dry matter of stressed plant $/$ Dry matter of control plant $] \times 100$

\subsection{Leaf Water Status}

Midday leaf water potential $\left(\Psi_{\mathrm{L}}\right)$ of control and stressed plants was measured with the help of pressure chamber (model 615, PMS Instrument, USA). All the measurements were taken on the fully expanded youngest leaves between 1000 to 1200 hours at weekly interval.

\subsection{Leaf Proline Content}

Free proline was extracted from $500 \mathrm{mg}$ of fully expanded fresh leaf samples homogenized with 3\% sulfosalicylic acid and estimated by using acid ninhydrin reagent according to the protocol of Bates et al. (1973). The absorbance of fraction with toluene aspired from liquid phase was determined by using UV-visible spectrophotometer (UV-1700 series, Pharma Spec, Japan) at 520 $\mathrm{nm}$. Contents of proline were expressed as $\mu \mathrm{mol} \mathrm{g}^{-1}$ fresh weight.

\subsection{Total Flavonoids and Anthocyanin Content}

Flavonoids and anthocyanin were extracted from fresh leaf discs by keeping them in acidified methanol (methanol: water: $\mathrm{HCl}, 78: 20: 2 \mathrm{~V} / \mathrm{V}$ ) for 24 hours at $4{ }^{\circ} \mathrm{C}$ (Jordan et al., 1994). The filtered extract was then used for measuring the absorbance at $320 \mathrm{~nm}$ and $530 \mathrm{~nm}$ for flavonoid and anthocyanin respectively which is indicative of relative concentration of light absorbing pigments. Flavonoid and anthocyanin contents were expressed as absorbance $\mathrm{g}^{-1}$ fresh weight of tissue at $320 \mathrm{~nm}$ and $530 \mathrm{~nm}$ respectively.

\subsection{Chlorophyll Degradation Percentage}

Leaf chlorophyll content was determined by the method of Anderson and Broadman (1964). Chlorophyll degradation percentage was then calculated using the formula given by Cha-Um and Kirdmanee (2008).

$$
\text { Chlorophyll degradation }(\%)=[1 \text {-chlorophyll of drought } / \text { chlorophyll of control }] \times 100
$$

\subsection{Seed Protein Content and Protein yield}

Seeds of both black gram and green gram were dried and grinded into powder for determination of seed protein content. At first, total nitrogen content was determined in CHN Analyzer (PerkinElmer 2400 Series II CHN/O Elemental Analyzer). Seed protein content and protein yield was then calculated by using the following formulae (Thalooth et al., 2006; Yagoob and Yagoob, 2014).

$$
\begin{aligned}
& \text { Seed protein content }(\%)=6.25 \times \text { total nitrogen }(\%) \\
& \text { Protein Yield }\left(\mathrm{q} \mathrm{ha}^{-1}\right)=\text { Protein }(\%) \times \text { seed yield }\left(\mathrm{q} \mathrm{ha}^{-1}\right) .
\end{aligned}
$$

\subsection{Statistical Analysis}

Mean values were taken from the measurements of three replicates and the standard error (SE) of the means was calculated. Analysis of variance (ANOVA) was applied to determine the significance of the results between the genotypes, different treatments and the interaction effect of genotype and treatments. All the statistical analyses were done using the Statistical Package for Social Sciences (SPSS) for Windows (version 16.0). In this study, all the data are presented as pooled data of two years. 


\section{RESULTS}

\subsection{Leaf Area Index (LAI)}

Genotypes grown in well watered condition presented considerably higher values of leaf area index (LAI) while stressed plants tended to have lower values of LAI (Table 1). Water stress reduced LAI by $8-42 \%$ in T9, $14-54 \%$ in KU $301,5-41 \%$ in Pratap and $8-38 \%$ in SG 21-5. Drought-induced reduction in LAI was highest during vegetative stage. Irrespective of treatments, T9 and Pratap maintained higher LAI than rest of the genotypes. Analysis of the data revealed that the difference between drought treatments with regard to LAI was statistically significant $(\mathrm{p} \leq 0.01)$ for both the crops.

\subsection{Plant Height Stress Tolerance Index (PHSI) and Dry Matter Stress Tolerance Index (DMSI)}

All the genotypes of black gram and green gram showed a considerable difference in terms of plant height stress tolerance index (PHSI) and dry matter stress tolerance index (DMSI) at all three growth stages (Fig. 1- A. B. C. D). Regardless of treatments, lower values of these two indices was recorded in the genotypes KU 301 (black gram) and SG 21-5 (green gram) while compared to other two genotypes. Higher maintenance of PHSI and DMSI by T9 and Pratap is an indication of their better performance under water deficit condition.

\subsection{Leaf Water Potential $\left(\Psi_{L}\right)$}

Leaf water potential $\left(\Psi_{\mathrm{L}}\right)$ values of all the genotypes grown under control and stress conditions are presented in Table 1. Application of drought for fifteen consecutive days significantly decreased $(\mathrm{p} \leq 0.05) \Psi_{\mathrm{L}}$ and it was more prominent during flowering stage. Under control condition, the recorded $\Psi_{\mathrm{L}}$ for black gram and green gram ranged from -1.11 to $-1.62 \mathrm{M} \mathrm{Pa}$ and -1.43 to $-2.70 \mathrm{M}$ Pa respectively. But under stress condition, these values dropped down to the level of -1.43 to $-2.70 \mathrm{M} \mathrm{Pa}$ in black gram and -1.81 to $-2.72 \mathrm{M} \mathrm{Pa} \mathrm{M} \mathrm{Pa} \mathrm{in} \mathrm{green} \mathrm{gram.} \mathrm{In} \mathrm{case} \mathrm{of}$ black gram, genotype T9 maintained higher $\Psi_{\mathrm{L}}$ at all the growth stages and in green gram, the same was recorded in Pratap. For both the crops, treatment difference was found to be statistically significant $(\mathrm{p} \leq 0.01)$ for $\Psi_{\mathrm{L}}$.

Table 1. Drought induced changes in leaf water potential $\left(\Psi_{\mathrm{L}}\right)$ and leaf area index (LAI) of black gram and green gram genotypes (mean \pm standard error)

\begin{tabular}{lllccr}
\hline \multirow{2}{*}{ Genotypes } & \multicolumn{2}{c}{ Leaf water potential (-M Pa) } & \multicolumn{2}{c}{ LAI } \\
& Stages & Non-stress & Stress & Non-stress & Stress \\
\hline \multirow{2}{*}{ T9 } & Vegetative & $1.11 \pm 0.04$ & $1.81 \pm 0.09$ & $0.38 \pm 0.04$ & $0.22 \pm 0.02$ \\
& Flowering & $1.51 \pm 0.03$ & $2.62 \pm 0.17$ & $0.69 \pm 0.05$ & $0.55 \pm 0.03$ \\
& Pod filling & $1.62 \pm 0.09$ & $2.24 \pm 0.05$ & $1.08 \pm 0.12$ & $0.99 \pm 0.05$ \\
& Vegetative & $1.41 \pm 0.12$ & $1.43 \pm 0.12$ & $0.37 \pm 0.03$ & $0.17 \pm 0.02$ \\
KU 301 & Flowering & $1.52 \pm 0.13$ & $2.70 \pm 0.07$ & $0.65 \pm 0.02$ & $0.48 \pm 0.03$ \\
& Pod filling & $1.22 \pm 0.07$ & $2.43 \pm 0.15$ & $0.97 \pm 0.02$ & $0.87 \pm 0.01$ \\
& Vegetative & $0.91 \pm 0.11$ & $1.81 \pm 0.09$ & $0.29 \pm 0.05$ & $0.17 \pm 0.02$ \\
Pratap & Flowering & $1.52 \pm 0.05$ & $2.31 \pm 0.07$ & $0.89 \pm 0.03$ & $0.79 \pm 0.05$ \\
& Pod filling & $1.60 \pm 0.09$ & $2.23 \pm 0.05$ & $2.21 \pm 0.06$ & $1.15 \pm 0.07$ \\
& Vegetative & $1.71 \pm 0.12$ & $2.04 \pm 0.15$ & $0.39 \pm 0.05$ & $0.24 \pm 0.02$ \\
SG 21-5 & Flowering & $1.51 \pm 0.03$ & $2.72 \pm 0.07$ & $0.77 \pm 0.02$ & $0.65 \pm 0.02$ \\
& Pod filling & $1.73 \pm 0.07$ & $2.41 \pm 0.05$ & $0.95 \pm 0.03$ & $0.87 \pm 0.01$ \\
\hline
\end{tabular}




\subsection{Leaf Proline Content}

Application of stress significantly increased $(\mathrm{p} \leq 0.01)$ the level of leaf proline content of black gram and green gram (Fig. 2- A, B). The increased accumulation of proline in leaves due to drought stress was more pronounced at flowering stage than vegetative and pod filling stages. In all the treatments, T9 and Pratap recorded higher increment of proline than KU 301 and SG 21-5. Genotypes T9 and Pratap proved their better tolerance capacity to the applied drought by accumulating higher proline than rest of the genotypes.

\subsection{Total Flavonoids and Anthocyanin Content}

In the present experiment, an increasing trend of total flavonoid content was observed in stressed plants as compared to the plants grown under well watered environment (Fig. 2- C, D). Regardless of genotypes, highest increment of total flavonoids was observed in the plants treated with deficit irrigation during flowering stage. Genotypes T9 and Pratap recorded higher levels of total flavonoid than other two genotypes in all the treatments. However, this increment was nonsignificant with regard to genotypes, treatments and their interaction for both black gram and green gram.

Table 2. Seed protein content and protein yield of black gram and green gram genotypes (mean \pm standard error)

\begin{tabular}{lcccc}
\hline Genotypes & \multicolumn{4}{c}{ Seed protein (\%) } \\
\hline T9 & $\mathrm{T}_{1}$ & $\mathrm{~T}_{2}$ & $\mathrm{~T}_{3}$ & $\mathrm{~T}_{4}$ \\
KU 301 & $21.35 \pm 0.64$ & $20.09 \pm 1.18$ & $18.44 \pm 0.59$ & $19.16 \pm 1.20$ \\
Pratap & $21.81 \pm 1.04$ & $20.01 \pm 0.58$ & $17.22 \pm 0.46$ & $18.11 \pm 0.90$ \\
SG 21-5 & $22.56 \pm 1.21$ & $21.41 \pm 0.81$ & $19.06 \pm 0.61$ & $19.91 \pm 0.46$ \\
& $23.06 \pm 1.15$ & $21.28 \pm 0.62$ & $18.23 \pm 1.17$ & $19.09 \pm 0.94$ \\
\hline T9 & & Protein yield $(\mathrm{q} / \mathrm{ha})$ & \\
KU 301 & $237.77 \pm 1.19$ & $199.90 \pm 2.31$ & $141.07 \pm 1.19$ & $154.81 \pm 1.74$ \\
Pratap & $234.17 \pm 0.64$ & $166.62 \pm 2.08$ & $95.28 \pm 2.27$ & $109.57 \pm 1.42$ \\
SG 21-5 & $271.62 \pm 1.22$ & $214.25 \pm 1.15$ & $144.28 \pm 1.27$ & $164.06 \pm 0.58$ \\
\hline
\end{tabular}

Application of drought during vegetative, flowering and pod filling stages significantly increased anthocyanin content $(p \leq 0.01)$ of both the crops. Highest increment of anthocyanin was recorded in plants stressed during flowering stage while the lowest increment was noted in plants where drought was applied during pod filling stage (Fig. 2- E, F). This increment was more prominent in black gram genotype T9 and green gram genotype Pratap than rest of the genotypes. Genotypic variably, treatments difference and the interaction of genotype and treatment was found to statistically significant for black gram while in case of green gram, only the effect of drought treatment was found to be significant $(\mathrm{p} \leq 0.01)$. 


\subsection{Chlorophyll Degradation Percentage}

A perceptible difference for chlorophyll degradation percentage was observed among the genotypes of both the crops (Fig. 1- E, F). Mean values of the data indicated that genotypes T9 and Pratap were more efficient in maintaining their leaf chlorophyll as they presented lesser value of chlorophyll degradation percentage at all three growth stages. On the other hand, higher values of chlorophyll degradation percentage obtained for genotypes KU 301 and SG 21-5 is the indication of higher rate of chlorophyll degradation under drought.

\subsection{Seed Protein Content and Protein Yield}

To study the effect of drought on quality of produced seeds, seed protein content and protein yield were calculated at harvest. A significant reduction $(\mathrm{p} \leq 0.05)$ in seed protein content was recorded in treated plants as compared to the plants grown under well watered environment. Application of drought at flowering stage was found to be more detrimental to seed quality (in terms of protein content) than vegetative and pod filling stages (Table 2). In all the treatments, genotypes KU 301 (8-21\%) and SG 21-5 (8-21\%) suffered from greater reduction in seed protein content as compared to T9 (5-14\%) and Pratap (5-16\%). Quality deterioration in terms of protein yield was highest in $\mathrm{T}_{3}$ plants (T9-41\%, KU 301- 59\%, Pratap- 47\%, SG 21-5- $66 \%$ ) and it was in the order $\mathrm{T}_{3}>\mathrm{T}_{4}>\mathrm{T}_{2}$. Analysis of the data revealed that genotypic variability, treatments difference and the interactions effect of genotype and drought treatment was statistically significant $(\mathrm{p} \leq 0.01)$ for protein yield.

\section{DISCUSSION}

Reduced plant size, leaf area and leaf area index are the major mechanisms to moderate water use and to decrease injury under osmotic stress (Mitchell et al., 1998). Therefore, in our experiment, reduction in leaf area index (LAI) under drought can be attributed to reduced leaf expansion and may be considered as a defense mechanism to maintain water balance inside the cell. Studies conducted in wheat and pigeon pea indicates that water stress induced reductions in growth and yield are closely associated with reductions in LAI (Lopez et al., 1997; Dalirie et al., 2010). Higher maintenance of LAI by T9 and Pratap helped them to capture solar radiation within the canopy for active photosynthesis and production of dry matter (higher value of DMSI) even under the conditions of soil moisture deficit. This indicates that these two genotypes have better tolerance capacity to drought than KU 301 and SG 21-5.

At all the growth stages, genotypes T9 and Pratap proved their better ability to cope up with drought by maintaining higher values of plant height stress tolerance index (PHSI) and dry matter stress tolerance index (DMSI). Plant height is a function of cell division, enlargement and differentiation (Hussain et al., 2008). Under drought, suppression in the rate of cell division and cell expansion due to loss of cell turgor bring about a reduction in plant height which is the prime cause of reduced PHSI (Baroowa and Gogoi, 2012). In our study, differential response of the studied genotypes in terms of PHSI and DMSI is due the variation in their tolerance capacity to drought in terms of maintenance of active photosynthesis and accumulation of dry matter (Dalirie et al., 2010).

The observed changes in leaf water potential $\left(\Psi_{\mathrm{L}}\right)$ in our experiment is attributable to a change in osmotic pressure which is the osmotic component of water potential (Siddique et al., 2000). Highest reduction in $\Psi_{\mathrm{L}}$ observed during flowering stage indicates the vulnerability of this stage towards drought. During reproductive growth, water requirement of the crop is more and as plant has completed the vegetative phase so, cannot produce/increase the root volume for further uptake of water from soil. Moreover the water available in the cell is used up to meet the increasing demand of energy for regulation of all the vital processes related to development of sink resulting in reduction of water potential inside the cell. Drop-down of leaf water potential $\left(\Psi_{\mathrm{L}}\right)$ under drought was also reported by Liu et al. (2011) while conducting their experiment in six woody plant species in karst habitats of southwestern China. Better maintenance of $\Psi_{\mathrm{L}}$ by T9 and Pratap indicates their 
inherent tolerance capacity to cope better with the condition of soil moisture deficiency through accumulation of compatible solutes like proline (Fig. 2- A, B) inside the cell.

In this study, higher accumulation of proline by $\mathrm{T} 9$ and Pratap acted as an osmoticum and accounted for their higher drought tolerance capacity keeping the slope of water potential at the threshold of drought stress (Fig. 2- A, B). Our results are in confirmatory with the findings of Ghaderi et al. (2015) while conducting their experiment in strawberry cultivars. Accumulation of proline in plants under stress is a result of the reciprocal regulation of two pathways: up regulation of P5CS (Pyrroline-5-carboxylate synthase) and down regulation of ProDH (proline dehydrogenase) and P5C dehydrogenase (Bartels and Sunker, 2005; Mohammadkhani and Heidari, 2008). Kuznetsov and Shevyakova (1999) have pointed out the role of proline in adaptation of plants to the stress conditions due to its diverse biological effects such as osmotic regulation, antioxidant action, energy transfer and carbon and nitrogen source. Therefore, accumulation of proline can be advocated as a parameter for selection of drought tolerant genotype of black gram and green gram.

Flavonoids are secondary plant metabolites with antioxidant properties and play a significant role in plants resistance against unfavorable environmental condition (Mierziak et al., 2014). These compounds accumulated in plant tissue could help to protect themselves from damaging effects by acting as free radical scavenger (Chutipaijit et al., 2008). In our investigation, total flavonoids and anthocyanin content was found to increase in stressed plants of both black gram and green gram (Fig. 2- C, D, E, F) which is in consistent with earlier findings (Jaafar et al., 2012; Baroowa and Gogoi, 2013). This increased level of anthocyanin contents were associated with an enhanced resistance to water loss as the glycosides attached to the anthocyanin in vacuoles adjust the osmotic potential of the cells, thereby minimizing the water loss through evapotranspiration (Chutipaijit et al., 2008). 

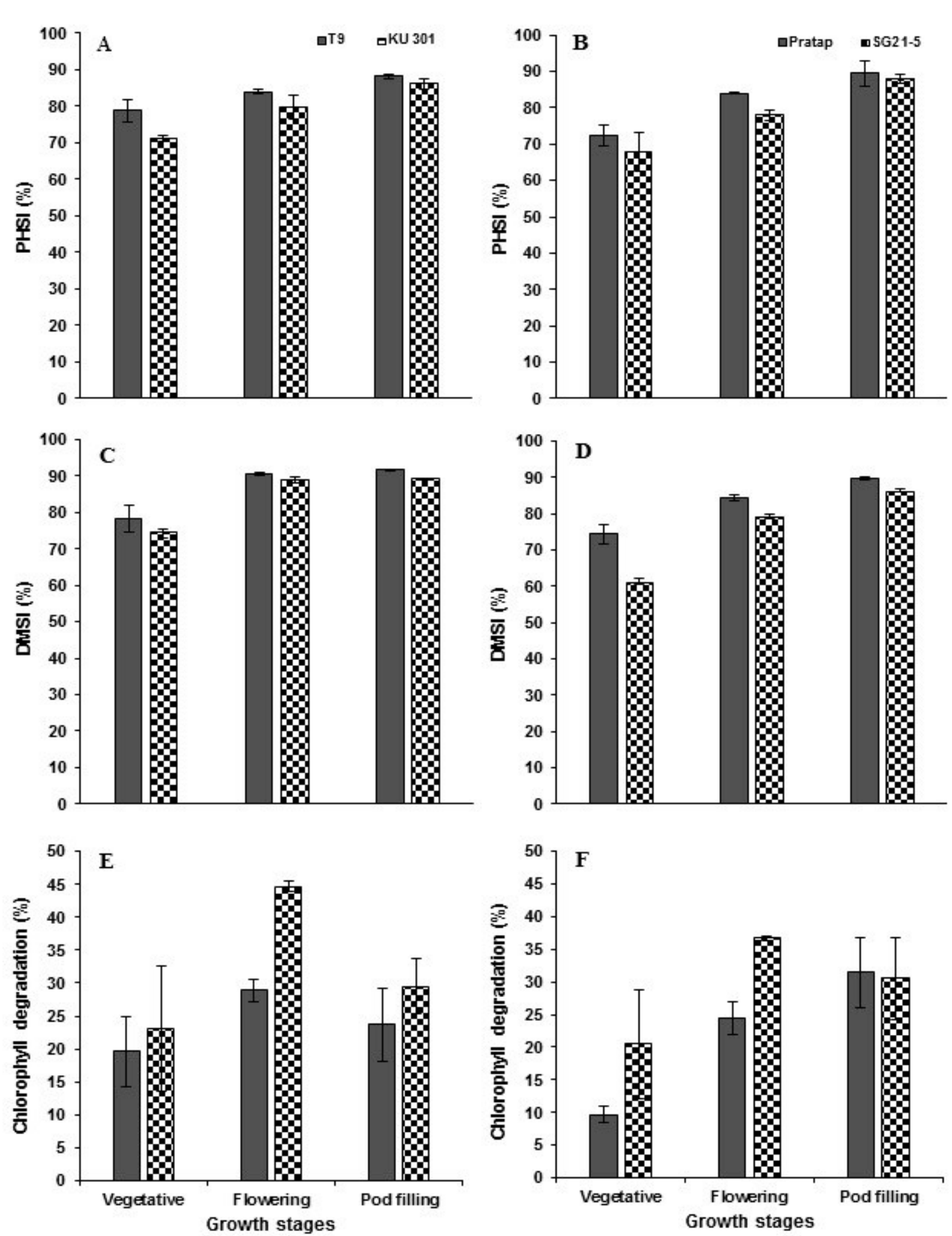

Fig. 1. Drought induced changes in PHSI- (A) black gram, (B) green gram, DMSI- (C) black gram, (D) green gram and chlorophyll degradation percentage- $(\mathrm{E})$ black gram and $(\mathrm{F})$ green gram (mean \pm standard error) 

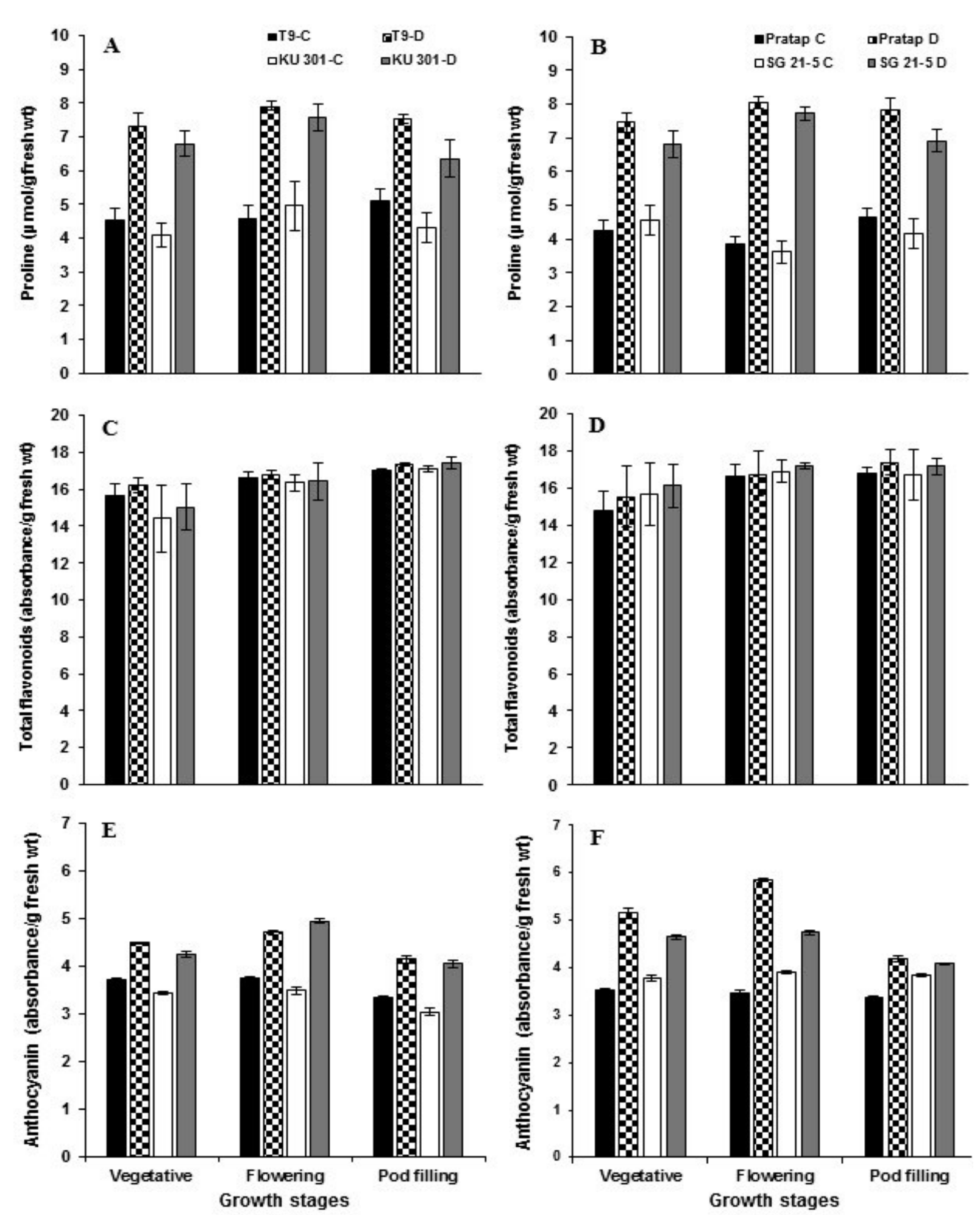

Fig. 2. Drought induced changes in the content of leaf proline-(A) black gram, (B) green gram, total flavonoids-(C black gram, (D) green gram and anthocyanin-(E) black gram, (F) green gram (mean \pm standard error)

Considerable difference in chlorophyll degradation percentage was observed among the studied genotypes of black gram and green gram. Higher values of chlorophyll degradation percentage proved the sensitivity of chlorophyll (the prime component of photosynthesis) to water deficit condition. The degradation of leaf chlorophyll content triggered by water deficiency might be due to injury of photosynthetic apparatus resulting from excessive swelling of chloroplast membranes, distortion of the lamellae vesiculation and the appearance of lipid droplets (Farooq et 
al., 2009). The production of reactive oxygen species (ROS) such as $\mathrm{O}_{2}{ }^{-}$and $\mathrm{H}_{2} \mathrm{O}_{2}$ causing lipid peroxidation is also one of the causes of chlorophyll destruction under drought (Alaei, 2011). In our experiment, a close association of chlorophyll degradation with $\Psi_{\mathrm{L}}$ was observed which in good agreement with the findings of Riaz et al. (2013).

Osmotic stress imposed at vegetative, flowering and pod filling stages greatly deteriorated the quality of black gram and green gram seeds. Under control condition, all the genotypes gave significantly higher $(\mathrm{p} \leq 0.01)$ percentage of seed protein and protein yield than drought treated plants (Table 2). Our results are in confirmatory with the findings of Ghanbari et al. (2013) while studying the response of some bean cultivars to drought. Fresneau et al. (2007) suggested that drought changes a number of physiological and biochemical processes including inhibition of protein synthesis consequently reducing the content of protein. This might be due to droughtinduced reduction of $\mathrm{N}$ partitioning and fixation leading to lower protein accumulation in the seeds (Singh, 2007). Induction of changes in proteins responding to water stress play a pivotal role in the adaptive mechanism of crops to drought (Riccardi et al., 1998). In general, the mineral nutrient contents change when environmental limitations affect the crop growth which reduces biomass at harvest, accompanied by less dilution of nutrients on a dry mass basis (Martinez-Ballesta et al., 2010). Therefore in our study, higher seed protein percentage and protein yield presented by the genotypes T9 and Pratap can be interlinked with the higher DMSI values and it is an indication of their higher capacity of nitrogen accumulation in the seeds under drought stress.

\section{CONCLUSION}

From this study, it can be concluded that the application of drought during different growth stages had a significant impact on both the pulses. Among the studied genotypes, T9 and Pratap presented higher values of LAI, PHSI, DMSI, proline, total flavonoids and anthocyanin, lower percentage of chlorophyll degradation and finally produced high quality seeds. Therefore, these two genotypes can be further exploited to improve genotypes tolerant to drought in the course of breeding and farmers can go for these two genotypes where irrigation facility is limited.

\section{References}

[1] Abbasi, A.R., R. Sarvestani, B. Mohammadi, A. Baghery, Drought stress-induced changes at physiological and biochemical levels in some common vetch (Vicia sativa L.) genotypes, J. Agric. Sci. Tech., 16 (2014) 505-516.

[2] Alaei, Y., The effect of amino acids on leaf chlorophyll content in bread wheat genotypes under drought stress conditions, Middle-East J. Sci. Res. 10 (2011) 99-101.

[3] Alcázar, R., J. Planas, T. Saxena, X. Zarza, C. Bortolotti, J. Cuevas, M. Bitrián, F. Antonio, A. F. Tiburcio, T. Altabella, Putrescine accumulation confers drought tolerance in transgenic arabidopsis plants over-expressing the homologous arginine decarboxylase gene, Plant Physiol. Bioch. 48 (2010) 547-552.

[4] Anjum, S.A., X. Xie, L. Wang, M.F. Saleem, C. Man, W. Lei, Morphological, physiological and biochemical responses of plants to drought stress, Afr. J. Agric. Res. 6 (2011) 20262032.

[5] Baroowa, B., N. Gogoi, Effect of induced drought on different growth and biochemical attributes of black gram (VignamungoL.) and green gram (Vigna radiate L.), J. Environ. Res. Develop. 6 (2012) 584-593.

[6] Bartels, D., R. Sunker, Drought and salt tolerance in plants. Crit. Rev. in Plant Sci. 24 (2005) 23-58.

[7] Bates, L.S., R.P. Waldren, I.D. Teare, Rapid determination of free proline for water-stress studies, Plant Soil 39 (1973) 205- 207.

[8] Castaneda-Saucedo, M.C., L. Crdova-Tellez, V.A. Gonzalez-Hernandez, A. DelgadoAlvarado, A. Santacruz-Varelaand, G. Garcia-de los Santos, Physiological performance, yield, and quality of dry bean seeds under drought stress, Interciencia 34 (2009) 748-754. 
[9] Cha-Um, S., C. Kirdmanee, Effect of osmotic stress on proline accumulation, photosynthetic abilities and growth of sugarcane plantlets (Saccharum officinarum L.), Pak. J. Bot. 40 (2008) 2541-2552.

[10] Chutipaijit, S., S. Cha-um, K. Sompornpailin, Influence of drought stress on proline and anthocyanin accumulations in indica rice cultivars, KMITL Sci. J. 8 (2008) 40-47.

[11] Dalirie, M.S., R.S. Sharifi, S. Farzaneh, Evaluation of yield, dry matter accumulation and leaf area index in wheat genotypes as affected by terminal drought stress, Not. Bot. Horti. Agrobo. 38 (2010) 182-186.

[12] Dos Santos, M.G., R.V. Ribeiro, R.F. de Oliveira, C. Pimentel, Gas exchange and yield response to foliar phosphorus application in Phaseolus vulgaris L. under drought, Braz. J. Plant Physiol. 16 (2004) 171-179.

[13] Farooq, M., A. Wahid, N. Kobayashi, D. Fujita, S.M.A. Basra, Plant drought stress: effects, mechanisms and management, Agron. Sustain. Dev. 29 (2009) 185-212.

[14] Fresneau, C., J. Ghashghaie, G. Cornic, Drought effect on nitrate reductase and sucrosephosphate synthase activities in wheat (Triticum durum L.): Role of leaf internal $\mathrm{CO}_{2}, \mathrm{~J}$. Exp. Bot. 10 (2007) 1-10.

[15] Ghaderi, N., S. Normohammadi, T. Javadi, Morpho-physiological responses of strawberry (fragaria $\times$ ananassa) to exogenous salicylic acid application under drought stress, J. Agric. Sci. Tech. 17 (2015) 167-178.

[16] Ghanbari, A.A., M.R. Shakiba, M. Toorchi, R. Choukan, Nitrogen changes in the leaves and accumulation of some minerals in the seeds of red, white and chitti beans (Phaseolus vulgaris) under water deficit conditions, Aust. J. Crop Sci. 7 (2013) 706-712.

[17] Hussain, M., M.A. Malik, M. Farooq, M.Y. Ashraf, M.A. Cheema, Improving drought tolerance by exogenous application of glycinebetaine and salicylic acid in sunflower, J. Agron. Crop Sci. 194 (2008) 193-199.

[18] Jaafar, H.Z., M.H. Ibrahim, N.F. Mohamad Fakri, Impact of soil field water capacity on secondary metabolites, phenylalanine ammonia-lyase (PAL), maliondialdehyde (MDA) and photosynthetic responses of malaysian kacip fatimah (Labisia pumila Benth). Molecules 17 (2012) 7305-7322.

[19] Jordan, B.R., P.E. James, A. Strid, R.G. Anthony, The effect of ultraviolet-b radiation on gene expression and pigment composition in etiolated and green pea leaf tissue: UV-B induced changes are gene-specific and dependent upon the development stage, Plant Cell Environ. 17 (1994) 45-54.

[20] Karuppanapandian, T., T. Karuppudurai, P.B. Sinha, A.H. Haniya, K. Manoharan, Genetic diversity in green gram [Vigna radiata (L.)] landraces analyzed by using random amplified polymorphic DNA (RAPD), Afr. J. Biotechnol. 5 (2006) 1214-1219.

[21] Kelly, J.D., P. Ramirez-Vallejo, Traits related to drought resistance in common bean. Euphytica 99 (1998) 43-50.

[22] Kuznetsov, V., N. Shevyakova, Proline under stress: biological role, metabolism and regulation, Russ. J. Plant Physiol. 46 (1999) 274-286.

[23] Liu, C., Y. Liu, K. Guo, D. Fan, G. Li, Y. Zheng, L. Yu, R. Yang, Effect of drought on pigments, osmotic adjustment and antioxidant enzymes in six woody plant species in karst habitats of southwestern China, Environ. Exp. Bot. 71 (2011) 174-183.

[24] Lopez, F.B., Y.S. Chauhan, C. Johansen, Effects of timing of drought stress on leaf area development and canopy light interception of short-duration pigeonpea, J. Agron. Crop Sci. 178 (1997) 1-7.

[25] Manivannan, P., C.A. Jaleel, B. Sankar, A. Kishorekumar, R. Somasundaram, G.M. Alagu Lakshmanan, R. Panneerselvam, Growth, biochemical modifications and proline metabolism in Helianthus Annuus L. as induced by drought stress, Colloids Surf. B: Biointerf. 59 (2007) 141-149. 
[26] Martinez-Ballesta, M.C., R. Dominguez-Perles, D.A. Moreno, B. Muries, C. AlcarazLopez, E. Bastias, C. Garcia-Viguera, M. Carvajal, Minerals in plant food: effect of agricultural practices and role in human health, A Review. Agron. Sustain. Dev. 30 (2010) 295-309.

[27] Mierziak, J., K. Kostyn, A. Kulma, Flavonoids as important molecules of plant interactions with the environment, Molecules 19 (2014) 16240-16265.

[28] Mitchell, J.H., D. Siamhan, M.H. Wamala, J.B. Risimeri, E. Chinyamakobvu, S.A. Henderson, S. Fukai, The use of seedling leaf death scores for evaluation of drought resistance of rice, Field Crops Res. 55 (1998)129-139.

[29] Mohammadkhani, N., R. Heidari, Drought-induced accumulation of soluble sugars and proline in two maize varieties, World Appl. Sci. J. 3 (2008): 448-453.

[30] Moosavi, S.G., The effect of water deficit stress and nitrogen fertilizer levels on morphology traits, yield and leaf area index in maize, Pak. J. Bot. 44 (2012) 1351-1355.

[31] Muchow, R.C., Canopy development in grain legumes grown under DiHerenl soil water regimes in a semi-arid tropical environment, Field Crops Res. 11 (1985) 99 -109.

[32] Nawaz, F., M.Y. Ashraf, R. Ahmad, E.A. Waraich, Selenium (Se) seed priming induced growth and biochemical changes in wheat under water deficit conditions, Biol. Trace Elem. Research 151 (2013) 284-293.

[33] Riaz, A.T.I.F., A. Younis, A.R. Taj, A. Karim, U. Tariq, S. Munir, S.I.T.W.A.T. Riaz, Effect of drought stress on growth and flowering of marigold (Tagetes erecta L.), Pak. J. Bot. 45 (2013) 123-131.

[34] Riccardi, F., P. Gazeau, D. de Vienne, M. Zivy, Protein changes in response to progressive water deficit in maize. Quantitative variation and polypeptide identification, Plant Physiol. 117 (1998) 1253-1263.

[35] Serraj, R., T. R. Sinclair, $\mathrm{N}_{2}$ fixation response to drought in common bean (Phaseolus vulgaris L.), Ann. Bot. 82 (1998) 229-234.

[36] Siddique, M.R.B, A. Hamid, M.S. Islam, Drought stress effects on water relations of wheat, Bot. Bull. Acad. Sinica. 41 (2000) 35-39.

[37] Singh, S., A.K. Gupta, N. Kaur, Differential responses of antioxidative defence system to long-term field drought in wheat (Triticum aestivum L.) genotypes differing in drought tolerance, J. Agron. Crop Sci. 198 (2012) 185-195.

[38] Singh S.P., Drought resistance in the race Durango dry bean landraces and cultivars, Agron. J. 99 (2007) 1219-1225.

[39] Yagoob, H., M. Yagoob, The effects of water deficit stress on protein yield of mung bean genotypes, Peak J. Agric. Sci. 2 (2014) 30-35. 